\title{
A study of histocompatibility antigens in patients with motor neuron disease in the northern region of England
}

\author{
E WOO, S NIGHTINGALE, DJ DICK, ${ }^{*}$ TJ WALLS* JM FRENCH, D BATES \\ From the Department of Neurology, Royal Victoria Infirmary, and the Regional Neurological Centre,* \\ Newcastle upon Tyne, UK
}

SUMmARY Histocompatibility antigen (HLA A, B and DR) serotyping was performed on 65 patients with motor neuron disease in the northern region of England and compared to a large control population from the Newcastle upon Tyne area. Thirty two patients had amyotrophic lateral sclerosis, 17 had progressive bulbar palsy and 16 had progressive muscular atrophy. Ten patients had a more slowly progressive course. No significant HLA associations were observed in the motor neuron disease patients. Subdivision of the patients by the clinical course of their disease did not reveal any significant associations. Forty six motor neuron disease patients from the Newcastle upon Tyne area had a reduced frequency of HLA DR4 compared to the local control population. The relevance of histocompatibility antigens to the pathogenesis of motor neuron disease is discussed.

Several studies have demonstrated an increased frequency of certain HLA antigens in motor neuron disease. Behan et $a l^{1}$ found an increased incidence of HLA A2 and HLA A28 in 32 patients from the Glasgow area. Antel et $_{\text {al }}{ }^{2}$ demonstrated an increased frequency of HLA A3 in 44 patients in the Greater Boston area and further suggested that the presence of HLA A3 was associated with rapidly progressive disease. Jokelainen et $^{a^{3}}$ studied 12 Finnish subjects and found a possible association with HLA B40. Kott et $a l^{4}$ also found an increased frequency of HLA A3 among 33 Israeli patients. Bartfeld et $a l^{5}$ from New York reported a trend towards an increase in HLA Bw35 in their patients with motor neuron disease. There have been two previous studies ${ }^{6}$ which failed to show a significant relationship with any particular antigen in patients with motor neuron disease. We

Present address of S Nightingale: The Midland Centre for Neurosurgery and Neurology, Holly Lane, Smethwick, Birmingham, B677JX.

Address for reprint requests (and present address): Dr E Woo, Department of Medicine, University of Hong Kong, Queen Mary Hospital, Hong Kong.

Received 21 May 1985 and in revised form 25 August 1985. Accepted 28 August 1985 here report the HLA frequency in motor neuron disease patients in the northern region of England compared to the known frequencies of HLA antigens in a large group of healthy control subjects from the same region.

\section{Patients and methods}

\section{(a) Patients}

Fifty five patients who presented to the Neurological Department of the Royal Victoria Infirmary and to the Regional Neurological Centre, Newcastle General Hospital over the period January 1981 to June 1983 were studied. All had classical motor neuron disease at presentation or upon subsequent follow-up and all had electromyographic confirmation of the diagnosis. The patients ranged in age from 40 years to 79 years at presentation with a mean of 61.4 years. There were 32 men and 23 women, none of whom had any family history of motor neuron disease, Parkinsonism or dementia. Twenty seven of the patients had the predominant features of amyotrophic lateral sclerosis, 15 had bulbar palsy and 13 had progressive muscular atrophy.

A further 10 patients (seven men, three women) with motor neuron disease who had presented prior to January of 1981 but who had a relatively slowly progressive form of the disease and who were still alive at the time of assessment were included in the analysis. Five presented with amyotrophic lateral sclerosis, two with progressive bulbar palsy 
and three with progressive muscular atrophy.

The duration from the first symptom to June of 1983 ranged from 0.17 to 20 years with a mean of 3.35 years. The group of recently diagnosed patients had a mean duration of $2 \cdot 1$ years (range 0.17 to 8.0 ) and the patients diagnosed before January 1981 had a mean duration of 6.52 years (range $3 \cdot 1$ to 20). The control group for HLA studies consisted of 325 unrelated normal healthy blood donors in the Newcastle upon Tyne area. ${ }^{8}$ All 325 control subjects had HLA A and B serotypings performed but only 200 also had HLA DR typing undertaken.

\section{(b) Methods}

Twenty $\mathrm{ml}$ of heparinised blood and $5 \mathrm{ml}$ of clotted blood were collected from each patient and the samples analysed within 24 hours of collection. HLA A, B and DR serotyping were carried out by the modified lymphocytotoxic test ${ }^{9}$ using appropriate HLA antisera. The results are analysed for significance by chi-square testing with the application of Yates' correction factor.

\section{Results}

The results of the HLA typing in the 55 motor neuron disease patients presenting after January of 1981 and in the healthy control subjects are shown in columns $A$ and $B$ of the table. There is an increased frequency of HLA A1, B8, B15 and DR3 but in no case does this reach statistical significance ( $p>0 \cdot 1$ in all instances). There is a decreased frequency of HLA A2 and a more marked decrease in HLA DR4, but in neither case is this statistically significant.

The results of the HLA typing in the additional group of 10 patients with motor neuron disease who presented prior to January 1981 are shown in column $\mathrm{C}$ of the table. There is a similar trend towards an increase in HLA B15 and a decrease in HLA DR4 but the numbers are too small to reach statistical significance.

Since there is no evident difference between the newly diagnosed motor neuron disease patients and those presenting before January 1981, the groups are combined in column $\mathrm{D}$ of the table. It can be seen that the increase in HLA B15 antigen and the reduction in the frequency of HLA DR4 antigen in the patients of this group is again present but does not reach a significant value.

In columns $\mathrm{E}$ and $\mathrm{F}$ of the table the population of

Table HLA frequencies

\begin{tabular}{|c|c|c|c|c|c|c|c|c|c|c|c|c|}
\hline$H L A$ & $A$ & $\%$ & $B$ & $\%$ & $C$ & $\%$ & $D$ & $\%$ & $E$ & $\%$ & $F$ & $\%$ \\
\hline $\begin{array}{l}\text { A1 } \\
\text { A2 } \\
\text { A3 } \\
\text { A9 } \\
\text { A10 } \\
\text { A11 } \\
\text { A28 } \\
\text { Aw19 }\end{array}$ & $\begin{array}{r}26 \\
25 \\
12 \\
8 \\
2 \\
5 \\
4 \\
19\end{array}$ & $\begin{array}{r}47 \cdot 2 \\
45 \cdot 5 \\
21 \cdot 8 \\
14 \cdot 5 \\
3 \cdot 6 \\
9 \cdot 1 \\
7 \cdot 3 \\
34 \cdot 5\end{array}$ & $\begin{array}{r}112 \\
172 \\
86 \\
61 \\
27 \\
45 \\
26 \\
78\end{array}$ & $\begin{array}{r}34.5 \\
52.9 \\
26.5 \\
18.8 \\
8.3 \\
13.8 \\
8.0 \\
24.0\end{array}$ & $\begin{array}{c}4 \\
4 \\
3 \\
2 \\
1 \\
2 \\
1\end{array}$ & $\begin{array}{l}40 \\
40 \\
30 \\
20 \\
10 \\
20 \\
10\end{array}$ & $\begin{array}{r}30 \\
29 \\
15 \\
10 \\
3 \\
5 \\
6 \\
20\end{array}$ & $\begin{array}{r}46 \cdot 2 \\
44 \cdot 6 \\
23 \cdot 1 \\
15 \cdot 4 \\
4.6 \\
7 \cdot 7 \\
9 \cdot 2 \\
30 \cdot 8\end{array}$ & $\begin{array}{r}21 \\
22 \\
12 \\
8 \\
2 \\
4 \\
4 \\
13\end{array}$ & $\begin{array}{r}45 \cdot 6 \\
47 \cdot 8 \\
26 \cdot 1 \\
17 \cdot 4 \\
4 \cdot 3 \\
8 \cdot 7 \\
8 \cdot 7 \\
28 \cdot 3\end{array}$ & $\begin{array}{l}9 \\
7 \\
3 \\
2 \\
1 \\
1 \\
2 \\
7\end{array}$ & $\begin{array}{r}47 \cdot 4 \\
36 \cdot 8 \\
15 \cdot 8 \\
10 \cdot 5 \\
5 \cdot 3 \\
5 \cdot 3 \\
10 \cdot 5 \\
36 \cdot 8\end{array}$ \\
\hline $\begin{array}{l}\text { B5 } \\
\text { B7 } \\
\text { B8 } \\
\text { B13 } \\
\text { B14 } \\
\text { B15 } \\
\text { B16 } \\
\text { B17 } \\
\text { B27 } \\
\text { B40 } \\
\text { Bw35 } \\
\text { Bw44 }\end{array}$ & $\begin{array}{r}6 \\
17 \\
18 \\
1 \\
1 \\
11 \\
3 \\
6 \\
5 \\
10 \\
7 \\
14\end{array}$ & $\begin{array}{r}10.9 \\
30.9 \\
32.7 \\
1.8 \\
1.8 \\
20.0 \\
5.5 \\
10.9 \\
9.1 \\
18.2 \\
12.7 \\
25.5\end{array}$ & $\begin{array}{l}26 \\
98 \\
82 \\
15 \\
21 \\
44 \\
16 \\
36 \\
16 \\
41 \\
36 \\
94\end{array}$ & $\begin{array}{r}8.0 \\
30.2 \\
25.2 \\
4.6 \\
6.5 \\
13.5 \\
4.9 \\
11 \cdot 1 \\
4.9 \\
12.6 \\
11.1 \\
28.9\end{array}$ & $\begin{array}{r}-2 \\
5 \\
1 \\
2 \\
1 \\
- \\
- \\
1 \\
\end{array}$ & $\begin{array}{l}\overline{20} \\
50 \\
10 \\
\overline{20} \\
10 \\
- \\
- \\
- \\
10 \\
20\end{array}$ & $\begin{array}{r}6 \\
19 \\
23 \\
2 \\
1 \\
13 \\
4 \\
6 \\
5 \\
10 \\
8 \\
16\end{array}$ & $\begin{array}{r}9.2 \\
29.2 \\
35.4 \\
3.1 \\
1.5 \\
20.0 \\
6.1 \\
9.2 \\
7.7 \\
15.4 \\
12.3 \\
24.6\end{array}$ & $\begin{array}{r}6 \\
15 \\
17 \\
1 \\
1 \\
8 \\
3 \\
4 \\
2 \\
10 \\
5 \\
11\end{array}$ & $\begin{array}{r}13.0 \\
32.6 \\
36.9 \\
2.2 \\
2.2 \\
17.4 \\
6.5 \\
8.7 \\
4.3 \\
21.7 \\
10.9 \\
23.9\end{array}$ & $\begin{array}{l}0 \\
4 \\
6 \\
1 \\
0 \\
5 \\
1 \\
2 \\
3 \\
0 \\
3 \\
5\end{array}$ & $\begin{array}{c}0 \\
21.0 \\
31.6 \\
5.3 \\
0 \\
26.3 \\
5.3 \\
10.5 \\
15.8 \\
0 \\
15.8 \\
26.3\end{array}$ \\
\hline $\begin{array}{l}\text { DR1 } \\
\text { DR2 } \\
\text { DR3 } \\
\text { DR4 } \\
\text { DR5 } \\
\text { DR6 } \\
\text { DR7 } \\
\text { DR8 }\end{array}$ & $\begin{array}{r}5 \\
15 \\
19 \\
13 \\
9 \\
5 \\
11 \\
1\end{array}$ & $\begin{array}{r}9.1 \\
27.3 \\
34.5 \\
23.6 \\
16.4 \\
9.1 \\
20.0 \\
1.8\end{array}$ & $\begin{array}{r}20 \\
63 \\
54 \\
70 \\
23 \\
34 \\
43 \\
4\end{array}$ & $\begin{array}{r}10 \cdot 0 \\
31.5 \\
27.0 \\
35.0 \\
11 \cdot 5 \\
17.0 \\
21.5 \\
2.0\end{array}$ & $\begin{array}{l}1 \\
4 \\
4 \\
1 \\
2 \\
1 \\
-\end{array}$ & $\begin{array}{l}10 \\
40 \\
40 \\
10 \\
20 \\
10 \\
-\end{array}$ & $\begin{array}{r}6 \\
19 \\
23 \\
14 \\
9 \\
7 \\
12 \\
1\end{array}$ & $\begin{array}{r}9.2 \\
29.2 \\
35.4 \\
21.5 \\
13.8 \\
10.8 \\
18.5 \\
1.5\end{array}$ & $\begin{array}{r}4 \\
16 \\
18 \\
8 \\
6 \\
5 \\
9 \\
0\end{array}$ & $\begin{array}{r}8.7 \\
34.8 \\
39.1 \\
17.4 \\
13.0 \\
10.9 \\
19.6 \\
0\end{array}$ & $\begin{array}{l}2 \\
3 \\
5 \\
6 \\
3 \\
2 \\
3 \\
1\end{array}$ & $\begin{array}{r}10.5 \\
15.8 \\
26.3 \\
31.6 \\
15.8 \\
10.5 \\
15.8 \\
5.3\end{array}$ \\
\hline $\mathbf{N}=$ & 55 & $\%$ & $\begin{array}{l}325 \text { (A B) } \\
200 \text { (DR) }\end{array}$ & $\%$ & 10 & $\%$ & 65 & $\%$ & 46 & $\%$ & 19 & $\%$ \\
\hline
\end{tabular}

A Recently diagnosed motor neuron disease patients.

B Control subjects.

C Slowly progressive motor neuron disease.

D Groups $A$ and $C$ combined.

E Motor neuron disease patients from the North East Region.

$F$ Motor neuron disease patients from Cumbria. 
patients with motor neuron disease is divided into those living in the north eastern part of the Region predominantly around the city of Newcastle upon Tyne and therefore more directly comparable with the control group and those from Cumbria who might theoretically be expected to have a different pattern of HLA antigen frequency. In the larger group of motor neuron disease patients from the Newcastle upon Tyne area the decrease of HLA DR4 $(\mathrm{p}<0.05)$ and the increase of HLA DR3 (not significant) compared to the control group are more marked than in the smaller Cumbrian population which has HLA frequencies more similar to those of the control population from the Newcastle upon Tyne area.

\section{Discussion}

Most of the reported HLA series in motor neuron disease have been retrospective. Since patients dying early in the course of the disease are not then studied the HLA distribution may be biased by factors which influence prognosis. When we began to analyse the HLA distribution in our patients in mid-1982, 15 patients, who had been diagnosed after January of 1981 as having motor neuron disease, had already died and are necessarily excluded from the study. However, the finding of a similar trend of distribution of HLA phenotypes in the groups of patients being diagnosed prior to and after January 1981 suggest that there is probably no significant difference between the HLA phenotypes of the patients with acute or more chronic forms of the disease.

Previous studies of HLA antigens in motor neuron disease have been limited to $A$ and $B$ loci $^{12457}$ except for two reports of HLA D frequencies. ${ }^{36}$ As the DR antigen is at present the closest marker of the HLA gene involved in regulating immune response (Ir gene), it is therefore particularly relevant to study the DR locus in a disease which might possibly have an immune pathogenesis. ${ }^{10}$ This study is the largest series of patients in whom DR serotype has been determined and we have shown a small but not statistically significant reduction in the DR4 phenotype. However, if the absence of the DR4 antigen were important in the pathogenesis of motor neuron disease, it is difficult to account for the unexpected finding of a relatively higher frequency of DR4 antigen in the motor neuron disease patients from Cumbria, when this region has been recognised to have a particularly high incidence of motor neuron disease (Quizilbash and Bates, unpublished). Although immunological mechanisms may have an important role in the pathogenesis of this relentless disease, the results of different HLA antigen studies from various centres throughout the world would argue against a strong association of motor neuron disease with any particular antigen. It is to be hoped that with the increased availability of DR locus typing, more studies will be undertaken to assess the importance of these antigens in motor neuron disease.

We gratefully acknowledge the assistance of the late Mr Patrick J Dewar formerly of the Northern Regional Transfusion Centre, Westgate Road, Newcastle upon Tyne.

\section{References}

${ }^{1}$ Behan PO, Durward WF, Dick H. Histocompatibility antigens associated with motor neurone disease. Lancet 1976;ii:803.

${ }^{2}$ Antel JP, Arnason BGW, Fuller TC, Lehrich, JR. Histocompatibility typing in amyotrophic lateral sclerosis. Arch Neurol 1976;33:423-5.

${ }^{3}$ Jokelainen M, Tiilikainen A, Lapinleimu L. Poliomyelitis antibodies and HLA antigens in amyotrophic lateral sclerosis. Tissue Antigens 1977;10:259-66.

${ }^{4}$ Kott E, Livni E, Zamir R, Kuritzky A. Cell-mediated immunity to poliomyelitis and HLA antigens in amyotrophic lateral sclerosis. Neurology (Minneap) 1979;29:1040-4.

${ }^{5}$ Bartfeld H, Pollack MS, Cunningham-Rundles S, Donnenfeld $H$. HLA frequencies in amyotrophic lateral sclerosis. Arch Neurol 1982;39:270-1.

${ }^{6}$ Pedersen L, Platz P, Jersild C, Thomsen M. HLA (SD and LD) in patients with amyotrophic lateral sclerosis. $J$ Neurol Sci 1977;31:313-8.

${ }^{7}$ Seignalet J, Cadilhac J, Lapinski H. HLA et sclerose laterale amyotrophique. Sem Hop Paris 1979;55:1239-40.

${ }^{8}$ Dewar PJ. HLA antigens. Clin Rheum Dis 1983;9:93-116.

${ }^{9}$ Mittal KK, Mickey MR, Singal DP, Terasaki PI. Serotyping for homotransplantation. Transplantation 1968; 6:913-27.

${ }^{10}$ Gurney ME, Belton AC, Cashman N, Antel JP. Inhibition of terminal axonal sprouting by serum from patients with amyotrophic lateral sclerosis. $N$ Engl $J$ Med 1984;311:933-9. 